\title{
DESIGN OF FLOATING HANDLEBAR SUSPENSION
}

\author{
Sandesh Bhaskar ${ }^{1}$, Vishnu Padmanaban ${ }^{2}$ \\ ${ }^{I}$ Third year B.Tech, Department of Mechanical Engineering, Amrita school of engineering, Amrita Vishwa \\ Vidyapeetham, Coimbatore, Tamil Nadu, India \\ ${ }^{2}$ Fourth year B.Tech, Department of Mechanical Engineering, Amrita school of engineering, Amrita Vishwa \\ Vidyapeetham, Coimbatore, Tamil Nadu,India
}

\begin{abstract}
An alternative to the conventional telescopic fork type front suspension used in bicycles is the Floating handle bar suspension which replaces the two springs that are used in the Telescopic forks by a single open coiled spring of a greater wire diameter and stiffness thereby eliminating the need of telescopic forks. In our study we determine the spring that is to be used to produce the required suspension effect. The newly designed spring was integrated to the bicycle and the model was validated by a working prototype which was ridden to check for any failures. The bicycle model used for checking the effectiveness of floating handlebar suspension was a Hercules Terminator V2. One major problem that we faced was the maneuverability of the bicycle during hard turns. This was due to the increase in weight of the front suspension.
\end{abstract}

Keywords: Bobbing, MR Fluids, Suspension, Telescopic Forks

\section{INTRODUCTION}

At a time when there were no suspension systems the vibrational stresses on vehicle riders did not only affect riding comfort but also impaired the rider's capability of perception and reaction as well. It even caused damage to the riders health[1,2]. Studies were done in the late 1990's on the effect of vibrational stresses on cyclists and the study was concluded by introducing a suspension followed by the study of vibrational comfort of bicycles[3][4]. The empirical basis for the comparison is a set of extensive measuring data concerning weighted accelerations on the human body, depending on bicycle design, rider mass, and road surfaces, the majority of which were cycle tracks[5]. The main purpose of introducing suspension system to bicycles is to improve the bicycle comfort and handling, by dissipating terrain induced energy. This addition of suspension systems also lead to the dissipation of cyclist's energy through small oscillatory movements termed as Bobbing [6][7][8][9]. The advantages include enhanced cycling velocity and braking capacity due to shock absorption [10]. The traditional choice in bicycles has been the telescopic fork type suspension and for many years there has not been much of progress in improvising or replacing the conventional front suspension. Telescopic forks are basically prismatic joints, thus the static friction between the sliding parts cannot be eliminated and this is usually experienced as a poor response to small road excitations for example negotiating a bump while leaning[11]. Bicycles with front suspension are majorly used by the children in the age group of 12-20 and their rough usage of bicycles also lead to jamming of the suspension system when they hit on hard bumps, this shows us that the load carrying capacity of the conventionally used springs in the front telescopic suspension is less. When the front suspension gets jammed people also generally find it difficult to service their jammed suspension as it remains concealed and often prefer buying a new suspension set. The introduction of Floating handlebar suspension, increases to a large extent the load carrying capacity as a stiffer spring is used. The spring used to give the suspension effect is no more concealed, in case of any problems people can service it themselves as it is just a matter of unscrewing and replacing the spring, thereby saving a lot of trouble and money.

\subsection{Spring Design Calculation}

Spring Specification:

Spring Material $=$ Chrome silicon steel

Wire diameter, $\mathrm{d}=5 \mathrm{~mm}$

Mean coil diameter, $\mathrm{D}=45 \mathrm{~mm}$

Number of active coils $=6$

Weight of the bicycle $=9 \mathrm{kgs}$

Let Weight of single person $=70 \mathrm{kgs}$

Total weight $=9+70=79 \mathrm{kgs}$

Front Suspension $=35 \%$

$35 \%$ of $79=27.65 \mathrm{kgs}$

Considering dynamic loads it will be double,

$\mathrm{W}=55.3 \mathrm{kgs}$

Spring Force, $\mathrm{F}=55.3 * 9.81=542.493 \mathrm{~N}$

Solid length $=30 \mathrm{~mm}$

Spring deflection $=47.88 \mathrm{~mm}$

Energy stored $=12.99 \mathrm{~J}$

Stiffness, $\mathrm{K}=11.33 * 10^{3} \mathrm{~N} / \mathrm{m}$

Free length of spring $=77.8 \mathrm{~mm}$

Pitch of lead $=12.98 \mathrm{~mm}$

Shear stress $=\quad 497.32 \mathrm{Mpa}$

\subsection{Experimental Validation}

A prototype of the proposed model was made. For prototyping, a Hercules Terminator V2 model was used. This model was chosen because it does not have a front suspension system and hence it will be easier for us to study the effect of the floating handlebar suspension. The handle 
bar of the model was replaced with an aluminum handlebar that has a fixed rotation about the horizontal axis and unlike other handlebars which are welded to the stem. In our prototype the handlebar was connected using a pin joint.

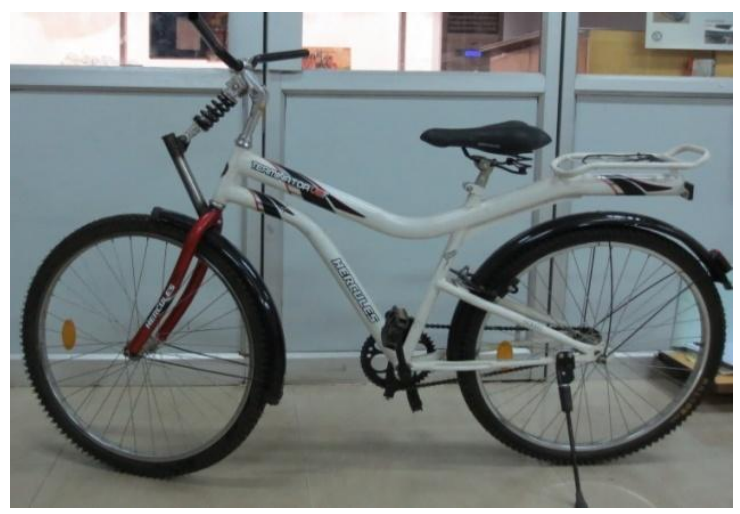

Model: Hercules Terminator V2

The rotation is possible because of the pin type link that is used to connect the stem and the head tube. Now to hold the spring intact two $U$ joints were used. These are similar to the ones used to hold the springs in the bicycles that have a rear suspension system. The first joint was welded to the stem, to hold the other joint and to fix the spring a supplementary steel rod was used. This steel rod was welded at the fork split area and hence was projected at an angle that was manually chosen to accommodate the length of the spring. The joint was welded to the rod and hence the spring was held between these joints to provide the necessary suspension effect.

\section{IMAGES}

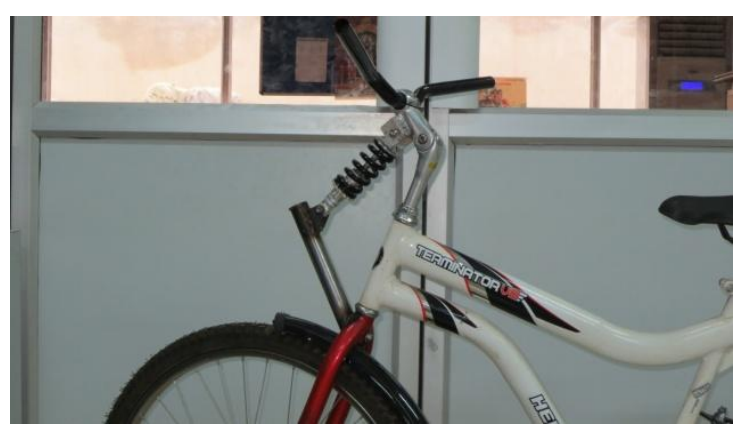

Floating Handlebar suspension (Closer look)

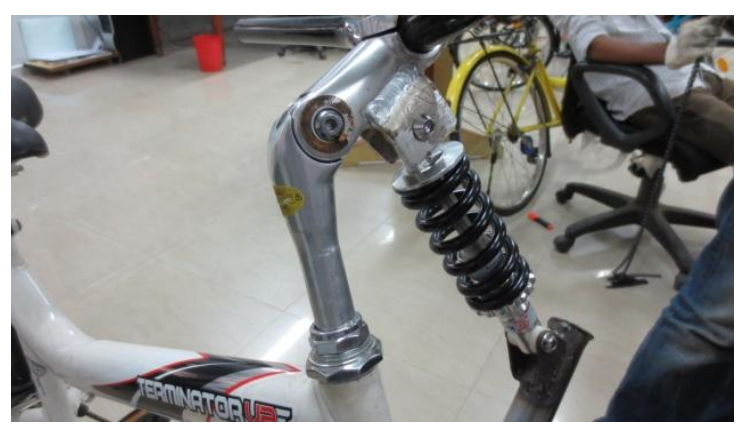

Different view of the suspension

\section{CONCLUSIONS}

The prototype was successfully built and was ridden to test for its suspension effect. It proved to handle loads more effectively. Some problems that this model faced was maneuverability at hard turns as the spring system adds to the weight of the handlebar. It adds about $.523 \mathrm{~g}$ to the existing system. In order to overcome the problem of increased weight at the handlebar we can replace the spring mass system with a Magnetorheological(MR) fluid system which will reduce the weight of the system to a great extent and hence help in easier maneuverability during turns. Further research is to be carried out on the same.

\section{ACKNOWLEDGEMENTS}

We would like to personally thank Mr. Caran from TI Cycles, India for his support and TI Cycles for providing us with the necessary resources to carry out the project.

\section{REFERENCES}

[1]. ISO: Guide for The Evaluation of Human Exposure to Whole-Body Vibration. International Standard 2631, International Organization for Standardization, 1985.

[2]. VDI: Einwirkungen mechanischer Schwingungen auf den Menschen (Effects of Mechanical Vibrations to Humans). VDI-Richtlinie 2057, Verein Deutscher Ingenieure, Duesseldorf, 1987

[3]. Waechter, M., Zacharias, N. and Riess, F.: Measurement and Simulation of the Vibrational Stress on Cyclists. Proceedings of the 3rd European Seminar on Velomobile Design, August 1998, Roskilde, Denmark, ISBN 87-987188-0-0

[4]. Waechter, M., Zacharias, N. and Riess, F.: Abschlussbericht des Forschungsprojektes 'Simulation des Schwingkomforts gefederter Fahrraeder" (Final Report of the Research Projekt "Simulation of the Vibrational Comfort of Bicycles with Suspension"). Faculty of Physics, Carl-von-Ossietzky University, Oldenburg, 1999

[5]. Matthias Waechter, Falkreiss

and Norbert Zacharias. A Multi-body Model for the Simulation of Bicycle Suspension Systems Vehicle system Dynamics 2002, Vol. 37, No.1, pp.3-28

[6]. Needle SA, Hull ML. An off-road bicycle with adjustable suspension kinematics Cycling Sci 1997; 1: 4-29

[7]. Wang EL, Hull ML. A dynamic system model of an offroad cyclist J Biomech Eng 1997; 119: 248-53

[8]. Wang EL, Hull ML. Power dissipated by off-road bicycle suspension systems. Cycling Sci 1994; 4: 10-26

[9]. Wang EL, Hull ML. Minimization of pedaling induced energy losses in off-road bicycle rear suspension systems. Vehicle Syst Dynam 1997; 28: 291-306

[10]. Olsen J. Bicycle suspension systems. In: Burke ER, editor. High-tech cycling Champaign (IL): Human Kinetics, 1996: 45-64

[11]. Basileos Mavroudakis, Peter Eberheard. "Analysis of Alternative Front Suspension Systems for Motorcycles" Vehicle system dynamics, August 2005 


\section{BIOGRAPHIES}

Sandesh Bhaskar is a third year
Mechanical Engineering student pursuing
Bachelor of Technology degree from
Amrita Vishwa Vidyapeetham, Tamil
Nadu

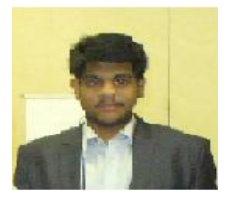

Vishnu Padmanaban is a fourth year Mechanical Engineering student pursuing Bachelor of Technology degree from Amrita Vishwa Vidyapeetham, Tamil Nadu. 